Report

\title{
RhoC-GTPase is a novel tissue biomarker associated with biologically aggressive carcinomas of the breast
}

\author{
Celina G. Kleer ${ }^{1,5}$, Kent A. Griffith ${ }^{2,5}$, Michael S. Sabel ${ }^{3,5}$, Gary Gallagher ${ }^{1}$, Kenneth \\ L. van Golen ${ }^{4,5}$, Zhi-Fen $\mathrm{Wu}^{4,5}$, and Sofia D. Merajver ${ }^{4,5}$ \\ ${ }^{1}$ Department of Pathology and Internal Medicine; ${ }^{2}$ Department of Biostatistics and Internal Medicine; ${ }^{3}$ Department of \\ Surgery and Internal Medicine; ${ }^{4}$ Division of Hematology/Oncology; ${ }^{5}$ Comprehensive Cancer Center, University of \\ Michigan, Ann Arbour, MI, USA
}

Key words: Rhoc, breast cancer, biomarkers, tissue microarrays, inflammatory breast cancer, pathology

\begin{abstract}
Summary
Background. There is a need for reliable predictors of breast cancer aggressiveness that will further refine the staging classification and help guide the implementation of novel therapies. We have identified $\mathrm{RhoC}$ as being nearly always overexpressed in the most aggressive form of breast cancer, inflammatory breast cancer (IBC); in subsequent work we identified $\mathrm{RhoC}$ to be a promising marker of aggressive behavior in breast cancers less than $1 \mathrm{~cm}$ in diameter. We hypothesized that RhoC expression would identify aggressive, non-IBC tumors breast cancer patients at any stage with worse outcomes defined as recurrence and/or metastasis.

Methods. We constructed four high-density tissue microarrays (TMAs) using 801 tissue cores from 280 patients. These tissues represent a wide range of normal breast and breast disease, including intraductal hyperplasia, ductal carcinoma in situ (DCIS), invasive carcinomas, and distant metastases. The TMAs were immunostained using a polyclonal anti-RhoC antibody developed in our laboratory. Cytoplasmic RhoC expression was scored as negative, weak, moderate, or strong by a previously validated scoring schema.

Results. RhoC expression increases with breast cancer progression. All samples of normal breast epithelium had negative to weak staining, whereas staining intensity increased in hyperplasia, DCIS, invasive carcinoma, and metastases (Kruskal-Wallis $p<0.001$ ). In patients with invasive carcinoma, high RhoC expression was associated with features of aggressive behavior including high histologic grade, positive lymph nodes, and negative hormonal receptor status. High RhoC expression was a predictor of overall survival in patients with breast cancer (log rank test, $p=0.002$ ) and was associated with $100 \%$ increase in the risk of death as compared to patients with low RhoC expression. Importantly, high $\mathrm{RhoC}$ was an independent predictor of poor response to doxorubicin-based chemotherapy with a hazard ratio of 3.1 and a $95 \%$ CI of 1.2-7.7 $(p=0.02)$.

Conclusion. RhoC expression increases with breast cancer progression and $\mathrm{RhoC}$ protein level in tumor tissue is strongly associated with biologically aggressive invasive carcinomas of the breast. RhoC expression, if validated, may identify patients who are less likely benefit from doxorubicin therapy and suggests RhoC overexpression as a new target for intervention.
\end{abstract}

\section{Introduction}

Breast cancer remains the second most common cause of cancer related deaths for women in the United States [1]. With the most advanced current treatment options, it is a fact that once patients develop distant metastases, they succumb to the disease [2]. The most important prognostic indicators in breast cancer that are in current use in the clinic are components of the staging system, such as primary tumor size and the presence of lymph node metastases [3]. Although these parameters are the most powerful prognostic factors available, they are not as precise as desired in predicting which tumors will recur locally and/or metastasize distally [4]. There are small invasive carcinomas that follow an aggressive clinical course and large tumors that do not recur or metastasize. Approximately one-third of women with node-negative breast cancer experience recurrences, whereas approximately one-third of patients with positive lymph nodes are free of disease 10 years after the primary tumor diagnosis. In addition to size and lymph nodes, other morphologic features, such as histological grade, vascular invasion, and molecular markers have been investigated for their potential to predict outcome, but in general, they have had limited value so far [4-6]. These data highlight the need for more sensitive and specific markers of aggressive behavior.

Through a modified version of the differential display technique and in situ hybridization of breast tissues, we previously identified $\mathrm{RhoC}$, a gene involved in cell 
polarity and motility, as being overexpressed in the most lethal form of locally advanced breast cancers, inflammatory breast cancer (IBC) [7]. We demonstrated that RhoC functions as a transforming oncogene for human mammary epithelial cells giving rise to a highly motile and invasive phenotype [8,9]. Invasive breast carcinomas that developed metastases exhibited higher levels of RhoC protein than invasive carcinomas that did not metastasize [10]. This body of work led us to hypothesize that RhoC overexpression may occur early in breast cancer progression and that it may identify a group of invasive, non-IBC tumors with a highly aggressive phenotype.

\section{Methods}

\section{Selection of patients and tissue microarray development}

Breast tissues were obtained from the Surgical Pathology files at the University of Michigan with Institutional Review Board approval. A total of 280 cases $(n=801$ tissue microarray elements) were reviewed by the study pathologist (CGK) and arrayed in four high-density tissue microarrays (TMAs), as previously described $[11,12]$. At least three tissue cores $(0.6 \mathrm{~mm}$ diameter $)$ were sampled from each block to account for tumor heterogeneity. The TMAs contained the whole spectrum of breast pathology, with samples of normal breast $(n=76)$, intraductal hyperplasia $(n=26)$, ductal carcinoma in situ $(n=22)$, invasive carcinoma $(n=639)$, and breast cancer metastases $(n=38)$. The invasive carcinomas were obtained from 233 largely consecutive patients ( $n=639$ tissue microarray elements) with follow-up information at the University of Michigan between 1987 and 1991. Clinical and outcome information on the 233 patients was obtained by chart review performed by the surgeon on the study (MSS) with IRB approval. In our cohort of 233 breast cancer patients, 211 had follow-up information. The median duration of follow-up was 3.6 years (range 15 days-17 years). Clinical and pathological variables were determined following well-established criteria. The histologic grade was assessed according to the method described by Elston and Ellis [13]; angiolymphatic invasion was classified as either present or absent.

\section{Immunohistochemical studies}

Immunohistochemistry was performed on the TMAs by using a standard biotin-avidin complex technique and a polyclonal antibody against $\mathrm{RhoC}$ that was previously validated by immunoblot and immunohistochemistry [10]. RhoC expression was evaluated at least three times for every tissue microarray element and at least nine times for each tumor, using an internet based tool (TMA Profiler, University of Michigan, Ann Arbor, MI) $[11,14]$. Using this method, the pathologist is blinded to tumor stage and clinical information. The median value of all measurements from a single individual was used for subsequent analyses. As observed previously [10], RhoC protein was strongly expressed in the cytoplasm of myoepithelial cells and vascular smooth muscle cells, which served as consistent internal positive controls. Cytoplasmic RhoC expression was scored from 1 to 4 by comparison to the positive internal controls $[10,11,15]$. Strong, diffuse staining was considered score $=4$, whereas moderate and low diffuse staining was scored as 3 and 2, respectively. Negative staining was scored as 1. Based on our previous work dealing with the biological characterization of RhoC as an oncogene, we defined high RhoC expression when there was strong staining (score $=4$ ) and low RhoC expression, when staining was negative, weak, or moderate (scores $=1-3$ ).

\section{Statistical analysis}

The association between $\mathrm{RhoC}$ protein expression and the pathologic diagnoses of the tissue microarray element was assessed using the general estimating equation. The ordinal expression categories for RhoC were modeled using the multinomial distribution with the cumulative logit link. Tissue microarray elements were clustered by patient. The model calculates the odds of a higher expression score versus a lower score, with the odds ratio and $95 \%$ confidence intervals reported.

The median RhoC expression score by patient was calculated for the subset of invasive carcinoma microarray elements. In instances where the calculated median was the midpoint between expression categories, the median was rounded to the higher category. Possible associations between the median RhoC expression score and clinical and pathologic features of the patient were assessed using the cumulative-logit multinomial model. Also called the proportional-odds model, the model calculates the odds of a higher expression score compared to a lower score across the ordinal categories of expression. The appropriateness of the proportionalodds assumption across categories was tested using the $\chi^{2}$ score test. The odds ratio and $95 \%$ confidence intervals are reported.

Overall survival time, time to breast cancer specific mortality, and time to treatment failure were calculated from the date of surgery until the subjects' date of death, date of death due to breast cancer, or the date of diagnosed treatment failure, respectively. Patients experiencing competing events were censored at the date of the competing event. For example, for calculations of breast cancer specific mortality, patients dying from other causes were censored on that date. Treatment failures included the diagnosis of local recurrence and the development of regional and distant metastases. Patients not experiencing any failure events were censored on their last date of follow-up or date of death. The analyzable sample included those patients with primary invasive tumor specimens arrayed for whom clinical follow-up data were available $(N=211)$.

Univariate associations between time-to-event endpoints and the clinical and pathologic characteristics, 
which included median RhoC expression, were assessed using the log-rank test statistic. The probability of events was estimated using the product-limit method of Kaplan and Meier. Multivariate associations were modeled using Cox proportional hazards regression. Clinical and pathologic characteristics with univariate log-rank test statistics with $p$-values less than $10 \%$ were included in multivariate models. The most parsimonious multivariate models were constructed using backward, stepwise elimination, with a $p$-value less than or equal to $5 \%$ necessary for a covariate to be retained. Hazard ratios and $95 \%$ confidence intervals are reported.

\section{Results}

\section{RhoC protein expression is elevated in breast cancer}

On the basis of our previous work characterizing RhoC as an oncogene in IBC and its protein expression in breast tissues, we sought to determine whether RhoC is upregulated as breast cancer develops. To this end, we evaluated the expression of $\mathrm{RhoC}$ protein in a wide range of breast tissues ( 280 cases, $n=801$ tissue microarray elements) by immunohistochemistry, to characterize its expression in situ. $\mathrm{RhoC}$ expression was observed mainly in the cytoplasm (Figure 1(a)), consistent with our previous observations [10]. Invasive breast carcinomas that expressed high levels of RhoC and those that expressed low levels of $\mathrm{RhoC}$ were readily apparent. RhoC protein levels were elevated in invasive carcinoma when compared to normal, intraductal hyperplasia, and DCIS (Table 1 and Figure 1). The odds of a higher RhoC expression levels were 2 times, 8 times, 12 times, and 8 times higher than normal epithelium, for intraductal hyperplasia, DCIS, invasive carcinoma, and metastatic deposits, respectively (Table 2).

Elevated RhoC expression is associated with aggressive breast cancer and poor prognosis

By using our breast cancer tissue microarray data, we evaluated the clinical pathological associations of RhoC

(a)

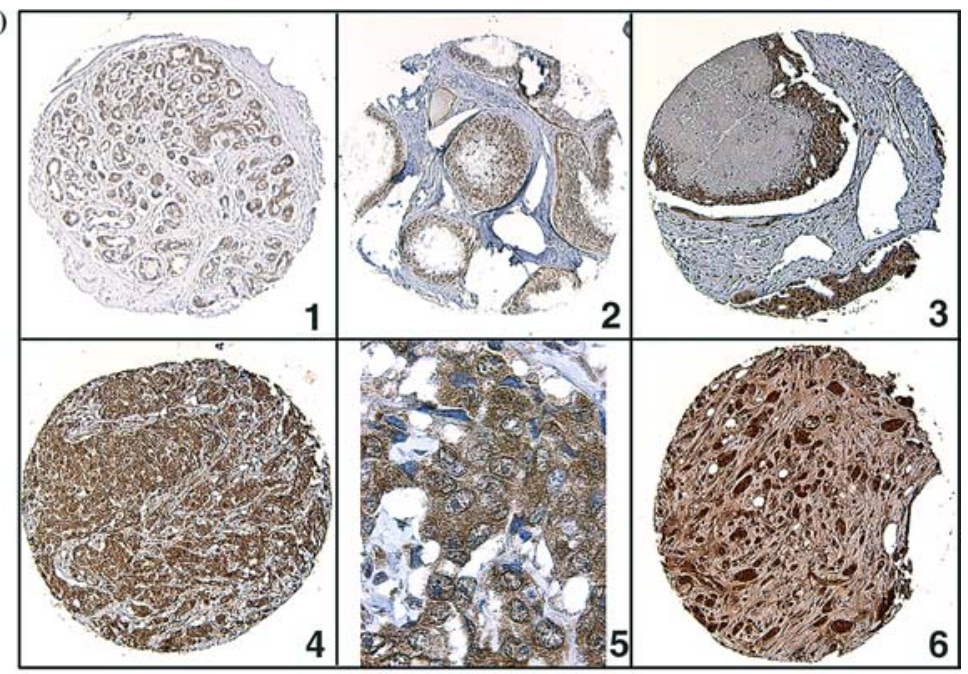

(b)

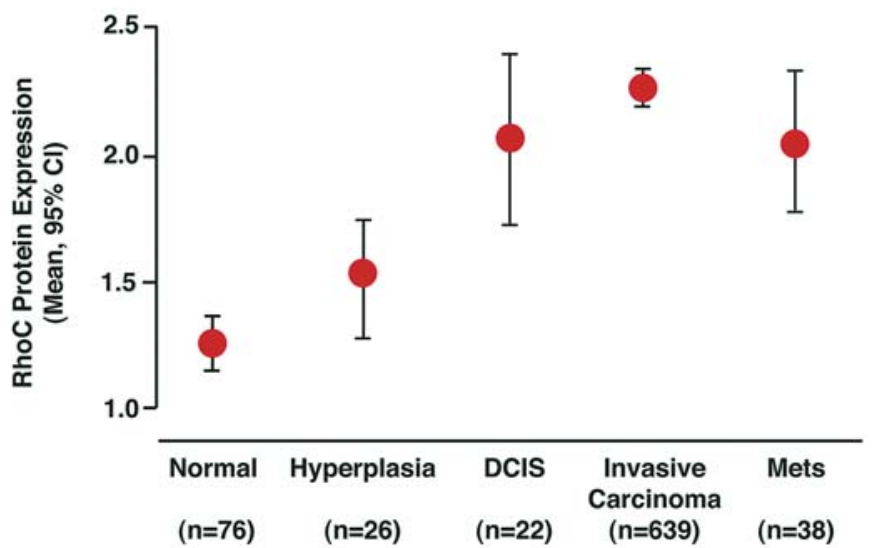

Figure 1. RhoC protein expression increases with breast cancer progression. (a) Tissue microarray samples of a normal breast lobule (1) and intraductal hyperplasia (2) with negative and weak RhoC expression. Ductal carcinoma in situ with comedo-necrosis (3) and invasive ductal carcinoma (4) with moderate and high RhoC expression, respectively. High power magnification of an invasive ductal carcinoma showing cytoplasmic accumulation of RhoC protein (5) Metastatic breast carcinoma in bone (6) with high expression of RhoC. (b) Mean RhoC expression increases with the severity of the diagnosis. Original magnification $40 \times$ and $100 \times$. 
Table 1. Frequency of RhoC protein expression in breast tissue samples as determined by immunohistochemistry

\begin{tabular}{|c|c|c|c|c|c|c|}
\hline \multirow[t]{2}{*}{ Breast tissue } & \multirow[t]{2}{*}{ Cores } & \multicolumn{4}{|c|}{ Staining intensity, $n(\%)$} & \multirow[t]{2}{*}{ Mean intensity } \\
\hline & & 1 & 2 & 3 & 4 & \\
\hline Normal epithelium & 76 & $58(76)$ & $16(21)$ & $2(3)$ & 0 & 1.26 \\
\hline Intraductal hyperplasia & 26 & $14(54)$ & $11(42)$ & $1(4)$ & 0 & 1.50 \\
\hline Ductal carcinoma in situ & 22 & $6(27)$ & $9(41)$ & $7(32)$ & 0 & 2.05 \\
\hline Invasive carcinoma & 639 & $140(22)$ & $249(39)$ & $203(32)$ & $47(7)$ & 2.25 \\
\hline Metastasis & 38 & $12(32)$ & $13(34)$ & $13(34)$ & 0 & 2.03 \\
\hline Total & 801 & & & & & 2.11 \\
\hline
\end{tabular}

Table 2. Odds of higher RhoC expression according to the tissue diagnosis

\begin{tabular}{lccr}
\hline Diagnosis & Odds ratio & 95\% CI & $p$-Value \\
\hline Normal epithelium & 1.00 & & \\
Intraductal hyperplasia & 2.46 & $1.01-6.00$ & 0.0487 \\
Ductal carcinoma in situ & 8.41 & $3.35-21.14$ & $<0.0001$ \\
Invasive carcinoma & 12.16 & $7.00-21.14$ & $<0.0001$ \\
Metastasis & 8.03 & $3.64-17.70$ & $<0.0001$ \\
\hline
\end{tabular}

protein levels in breast cancer. In our cohort of 233 breast cancer patients ( $n=801$ samples), 211 had follow-up information. The median age of the study population was 58 years (range 28-99 years). The clinical and pathological characteristics of the patients are summarized in Table 3. The breakdown of treatment modalities in this group of patients is summarized in Table 4 . Ninety-three patients $(44.1 \%)$ received chemotherapy following surgery. In 90 of 93 patients (97\%) the treatment consisted of a doxorubicin and cyclophosphamide combination regimen, with the remaining three patients receiving taxol alone.

After a median follow-up of 3.6 years (range: 15 days-17 years), 42 of the 226 patients (18.6\%) died of breast cancer. The 5- and 10-year disease specific survival rates for the entire cohort of patients were $60 \%$ and $38 \%$, respectively.

High RhoC expression was present in a subset of invasive carcinomas (13 of $211,6.2 \%)$. The association between RhoC protein levels and clinical characteristics is shown on Table 5. RhoC expression was strongly associated with the presence of positive axillary lymph nodes (Fisher's exact test, $p=0.0026$ ), one of the strongest known predictors of survival. High RhoC expression was also associated with increasing histologic tumor grade (Fisher's exact test, $p=0.016$ ), a measure of the degree of tumor differentiation and poor prognostic indicator. Grade II and III tumors were three and six times more likely to have a high RhoC expression when compared to grade I tumors, respectively. High RhoC expression was associated with negative estrogen receptor status (Fisher's exact test, $p=0.033$ ) and negative progesterone receptor status (Fisher's exact test, $p=0.004)$. Notably, despite the small number of tumors, RhoC overexpression was strongly associated with features of poor outcome in patients with breast cancer.

We next investigated the prognostic value of $\mathrm{RhoC}$ protein expression by interrogating the dataset about its prediction of aspects of the outcome in patients with newly diagnosed breast cancer. As expected, at the univariate level, the stage of disease, lymph node status, and histological tumor grade were associated with overall and disease-specific survival (Tables 6 and 7). Hormone receptor status was inversely associated with outcome. We found a strong and consistent association between RhoC protein levels and overall patient outcome. Higher RhoC protein levels were associated with all the important clinical outcomes that comprise "poor prognosis': shorter disease-free interval after initial surgical treatment, lower overall survival, and a high probability of breast cancer-specific death (Figure 2). The 10-year overall survival for patients with tumors expressing high RhoC levels was $23 \%$ and by contrast to $53 \%$ for low levels of RhoC (log rank, $p=0.002$, Figure $2 \mathrm{~b}$ ).

The best multivariable model predictive of overall survival included tumor stage, negative PR, the presence of vascular invasion, and treatment with radiotherapy, chemotherapy and tamoxifen (Table 8). High RhoC expression was a marginally significant independent predictor of outcome. Patients with high RhoC levels had a $100 \%$ higher risk of death when compared to patients with low RhoC expression (hazard ratio 2, 95\% CI 1.0-4.1, $p=0.067$ ).

\section{RhoC is a promising predictive factor of response to doxorubicin-based chemotherapy}

In our cohort of 211 breast cancer patients, 93 (44.1\%) received adjuvant chemotherapy consisting in 90 of the 93 patients of a doxorubicin and cyclophosphamide combination regimen (Table 4). We sought to determine whether RhoC expression could predict survival in chemotherapy treated patients. Tumor stage, positive lymph node status, estrogen and progesterone receptor status, lymphovascular invasion, tamoxifen use, and median RhoC expression all had significant univariate associations with survival for chemotherapy treated patients. The multivariate model indicates that median RhoC expression was found to be independently 
Table 3. Clinico-pathologic characteristics of the 211 patients with invasive carcinomas

\begin{tabular}{|c|c|}
\hline Characteristics & $N(\%)^{\dagger}$ \\
\hline \multicolumn{2}{|l|}{ Race } \\
\hline White & $172(81.5)$ \\
\hline Black & $26(12.3)$ \\
\hline Other/Unknown & $13(6.2)$ \\
\hline \multicolumn{2}{|l|}{ Menopause status } \\
\hline Pre & $43(20.4)$ \\
\hline Peri & $19(9.0)$ \\
\hline Post & $129(61.1)$ \\
\hline Unknown & $20(9.5)$ \\
\hline \multicolumn{2}{|l|}{ Breast cancer type } \\
\hline Ductal & $149(70.6)$ \\
\hline Lobular & $19(9.0)$ \\
\hline Ductal and Lobular & $9(4.3)$ \\
\hline Other/Unknown & $34(16.1)$ \\
\hline \multicolumn{2}{|l|}{ Tumor stage } \\
\hline I & $65(30.8)$ \\
\hline II & $72(34.1)$ \\
\hline III & $47(22.3)$ \\
\hline IV & $5(2.4)$ \\
\hline Unknown & $22(10.4)$ \\
\hline \multicolumn{2}{|l|}{ Tumor size $(\mathrm{cm})$} \\
\hline$\leq 2$ & $109(51.7)$ \\
\hline$>2$ & $85(40.3)$ \\
\hline Unknown & $17(8.0)$ \\
\hline \multicolumn{2}{|l|}{ Tumor grade } \\
\hline I & $24(11.4)$ \\
\hline II & $92(43.6)$ \\
\hline III & $77(36.5)$ \\
\hline Unknown & $18(8.5)$ \\
\hline \multicolumn{2}{|l|}{ Estrogen receptor } \\
\hline Positive & $137(64.9)$ \\
\hline Negative & $68(32.2)$ \\
\hline Unknown & $6(2.8)$ \\
\hline \multicolumn{2}{|l|}{ Progesterone receptor } \\
\hline Positive & $113(53.6)$ \\
\hline Negative & $92(43.6)$ \\
\hline Unknown & $6(2.8)$ \\
\hline \multicolumn{2}{|l|}{ Her2/Neu status } \\
\hline Positive over expressed & $36(17.7)$ \\
\hline Negative not over expressed & $165(77.6)$ \\
\hline Unknown & $10(4.7)$ \\
\hline \multicolumn{2}{|l|}{ Lymphovascular invasion } \\
\hline Present & $61(28.9)$ \\
\hline Absent & $147(69.7)$ \\
\hline Unknown & $3(1.4)$ \\
\hline \multicolumn{2}{|l|}{ Lymph nodes } \\
\hline Negative & $92(43.6)$ \\
\hline 1-3 positive nodes & $46(21.8)$ \\
\hline$>4$ positive nodes & $39(18.5)$ \\
\hline Unknown & $34(16.1)$ \\
\hline
\end{tabular}

Table 3. Continued

\begin{tabular}{ll}
\hline Characteristics & $N(\%)^{\dagger}$ \\
\hline Median RhoC expression & \\
1 & $33(15.6)$ \\
2 & $94(44.6)$ \\
3 & $71(33.7)$ \\
4 & $13(6.2)$ \\
\hline
\end{tabular}

Table 4. Treatment characteristics of the patients with invasive carcinomas $(N=211)$

\begin{tabular}{lc}
\hline Characteristics & $N(\%)^{\dagger}$ \\
\hline Neoadjuvant chemotherapy & $17(8.1)$ \\
Yes & $192(91.0)$ \\
No & $2(0.9)$ \\
Unknown & \\
Surgery type & $132(62.6)$ \\
Mastectomy & $74(35.1)$ \\
Lumpectomy & $5(2.4)$ \\
None/Unknown & \\
Adjuvant chemotherapy & $93(44.1)$ \\
Yes & $108(51.2)$ \\
No & $10(4.7)$ \\
Unknown & \\
Adjuvant radiotherapy & $95(45.0)$ \\
Yes & $104(49.3)$ \\
No & $12(5.7)$ \\
Unknown & \\
Tamoxifen therapy & $96(45.5)$ \\
Yes & $99(46.9)$ \\
No & $16(7.6)$ \\
Unknown &
\end{tabular}

associated with overall survival following chemotherapy, with a hazard ratio of 3.1 and a $95 \%$ CI of $1.2-7.7$ $(p=0.0176)$ (Table 9).

\section{Discussion}

In this study based on unselected patients with primary invasive carcinomas of the breast treated by standard of care at our institution between 1987 and 1991, we tested the hypothesis that $\mathrm{RhoC}$ protein levels are associated with highly aggressive breast cancer. Furthermore, we examined the expression of $\mathrm{RhoC}$ in the whole spectrum of breast tissues, ranging from normal breast, intraductal hyperplasia, ductal carcinoma in situ, invasive carcinomas, and breast cancer metastases. We found that a high level (4+) of RhoC protein is present only in invasive carcinomas and not present in normal breast epithelium, hyperplasia, or ductal carcinoma in situ. $\mathrm{RhoC}$ protein expression increased steadily from normal breast, to fibrocystic changes, to DCIS, and invasive carcinomas. The strongest $\mathrm{RhoC}$ expression was observed in locally advanced breast cancer and in 
Table 5. Association of RhoC expression with other clinical and pathologic features

\begin{tabular}{|c|c|c|c|c|c|}
\hline \multirow[t]{2}{*}{ Characteristic: } & \multirow{2}{*}{$\begin{array}{l}\text { Fisher's exact } \\
p \text {-value }\end{array}$} & \multicolumn{4}{|c|}{ Median RhoC Staining Intensity, $N(\%)$} \\
\hline & & 1 & 2 & 3 & 4 \\
\hline Tumor stage: & 0.8520 & & & & \\
\hline 1 & & $11(33.3)$ & $33(35.1)$ & 17 (23.9) & $4(30.8)$ \\
\hline 2 & & $10(30.3)$ & $29(30.9)$ & $29(40.9)$ & $4(30.8)$ \\
\hline 3 & & $9(27.3)$ & $17(18.1)$ & 17 (23.9) & $4(30.8)$ \\
\hline 4 & & 0 & $3(3.2)$ & $2(2.8)$ & 0 \\
\hline Tumor size $(\mathrm{cm})$ : & 0.5792 & & & & \\
\hline$\leq 2$ & & $11(33.3)$ & $38(40.4)$ & $32(45.1)$ & $4(30.8)$ \\
\hline$>2$ & & $19(57.6)$ & $51(54.3)$ & $32(45.1)$ & $7(53.9)$ \\
\hline Tumor grade: & 0.0166 & & & & \\
\hline I & & $8(24.2)$ & $13(13.8)$ & $3(4.2)$ & 0 \\
\hline II & & $14(42.4)$ & $43(45.7)$ & $31(43.7)$ & $4(30.8)$ \\
\hline III & & $9(27.3)$ & $29(30.9)$ & $30(42.3)$ & $9(69.2)$ \\
\hline Positive lymph nodes: & 0.0026 & & & & \\
\hline Zero & & $16(48.5)$ & $45(47.9)$ & $26(36.6)$ & $5(38.5)$ \\
\hline $1-3$ & & $4(12.1)$ & $19(20.2)$ & $21(29.6)$ & $2(15.4)$ \\
\hline $4+$ & & $9(27.3)$ & $10(10.6)$ & $16(22.5)$ & $4(30.8)$ \\
\hline Lymphovascular invasion: & 0.6962 & & & & \\
\hline Present & & $10(30.3)$ & $23(24.5)$ & $22(31.0)$ & $6(46.2)$ \\
\hline Absent & & $23(69.7)$ & $69(73.4)$ & $48(67.6)$ & $7(53.9)$ \\
\hline Estrogen receptor: & 0.0336 & & & & \\
\hline Positive & & $23(69.7)$ & $65(69.2)$ & $46(64.8)$ & $3(23.1)$ \\
\hline Negative & & $10(30.3)$ & $26(27.7)$ & $22(31.0)$ & $10(76.9)$ \\
\hline Progesterone receptor: & 0.0043 & & & & \\
\hline Positive & & $22(66.7)$ & $55(58.5)$ & $35(49.3)$ & $1(7.7)$ \\
\hline Negative & & $11(33.3)$ & $35(37.2)$ & $34(47.9)$ & $12(92.3)$ \\
\hline Her2/Neu expression: & 0.6965 & & & & \\
\hline Positive & & $4(12.1)$ & $15(15.9)$ & $15(21.1)$ & $2(15.4)$ \\
\hline Negative & & 29 (87.9) & 73 (77.6) & $52(73.2)$ & 11 (84.6) \\
\hline
\end{tabular}

metastatic breast cancer. These findings suggest that accumulation of RhoC protein is an early and progressive event in the development of breast cancer, thereby justifying efforts aimed at developing novel therapeutic interventions that may prevent the increase in RhoC protein expression.

In the group of patients with invasive carcinomas, very high RhoC expression occurred in a small subset (13 of $211,6.2 \%$ ). However, those patients with high levels of RhoC protein in the tumor cells had uniformly a worse outcome than patients with low RhoC expression, despite of aggressive multimodality treatment. Consistently, high RhoC expression was associated with positive lymph nodes, higher histologic grade, and with negative ER and PR protein expression, all known markers of more aggressive disease. Patients with high RhoC expression had a 5- and 10 -year overall survival of $57.5 \%$ and $23 \%$, respectively, in contrast to patients with low RhoC expression, who had a 5- and 10-year overall survival of $70.5 \%$ and $53 \%$, respectively (log rank test, $p=0.002)$. In the multivariable Cox regression analysis, patients with high RhoC levels had $100 \%$ increase in the risk of death as compared to patients with low RhoC levels (hazard ratio of $2,95 \% \mathrm{CI}$ of $1-4.1, p=0.067$ ). This suggests that RhoC overexpression is a specific alteration that occurs infrequently in early breast ancer, but when present, it signals a biologically aggressive tumor phenotype with high likelihood of recurrence and poor survival despite different treatment interventions. We suggest that this finding is clinically highly relevant and, if further validated, it may be the basis of a new clinically applicable test.

Notably, when we analyzed the predictive value of RhoC in a group of breast cancer patients treated uniformly with a combination regimen of doxorubicin and cyclophosphamide, high RhoC levels were independently associated with overall survival after chemotherapy. Although the number of patients with high RhoC expression is low overall, our data suggest that RhoC may identify a small group of patients who have a poor survival despite doxorubicin-based chemotherapy. This is clinically relevant because, if further validated in a larger cohort of uniformly treated patients, it may identify patients who might benefit from other chemotherapeutic agents or alternative molecular 
Table 6. Univariate analysis of overall survival

\begin{tabular}{|c|c|c|c|c|c|}
\hline \multirow[t]{2}{*}{ Characteristic } & \multicolumn{2}{|l|}{ 5-year } & \multicolumn{2}{|l|}{10 -year } & \multirow[t]{2}{*}{ Log-rank $p$-value } \\
\hline & Estimate & $95 \% \mathrm{CI}$ & Estimate & $95 \% \mathrm{CI}$ & \\
\hline Tumor stage & & & & & $<0.0001$ \\
\hline 1 & 83.5 & $73.5-93.5$ & 71.8 & $59.0-84.6$ & \\
\hline 2 & 78.2 & $68.0-88.4$ & 53.2 & $40.0-66.4$ & \\
\hline 3 or 4 & 47.5 & $33.3-61.5$ & 33.3 & $19.0-47.8$ & \\
\hline Estrogen receptor & & & & & 0.0078 \\
\hline Positive & 75.0 & $66.9-83.0$ & 55.8 & $45.9-65.7$ & \\
\hline Negative & 57.0 & $44.7-62.3$ & 39.4 & $26.6-52.2$ & \\
\hline Progesterone & & & & & 0.0001 \\
\hline Positive & 80.1 & $71.9-88.3$ & 62.4 & $51.7-73.0$ & \\
\hline Negative & 57.0 & $46.3-67.7$ & 37.4 & $26.2-48.5$ & \\
\hline Lymphovascular invasion & & & & & 0.0080 \\
\hline Absent & 74.1 & $66.2-82.0$ & 59.4 & $50.1-68.8$ & \\
\hline Present & 59.9 & $47.4-72.3$ & 34.7 & $21.6-47.9$ & \\
\hline Tumor grade & & & & & 0.0245 \\
\hline $\mathrm{I} / \mathrm{II}$ & 78.1 & $69.9-86.4$ & 58.8 & $48.2-69.3$ & \\
\hline III & 60.2 & $48.9-71.5$ & 42.0 & $30.1-54.0$ & \\
\hline Positive lymph nodes & & & & & 0.0010 \\
\hline Zero & 82.4 & $73.9-90.9$ & 66.5 & $55.3-77.7$ & \\
\hline $1-3$ & 78.1 & $65.3-90.8$ & 56.3 & $39.7-72.9$ & \\
\hline $4+$ & 53.7 & $37.3-70.0$ & 37.4 & $19.8-54.9$ & \\
\hline Tamoxifen use & & & & & 0.0447 \\
\hline Yes & 83.4 & $75.4-91.5$ & 61.1 & $49.4-72.7$ & \\
\hline No & 62.0 & $52.1-71.9$ & 45.1 & $34.5-55.8$ & \\
\hline \multicolumn{6}{|l|}{ Median RhoC expression } \\
\hline 1 & 80.8 & $65.1-96.5$ & 58.0 & $35.9-80.1$ & 0.0209 \\
\hline 2 & 69.3 & $59.6-79.1$ & 48.5 & $37.4-59.7$ & \\
\hline 3 & 67.6 & $55.8-79.5$ & 56.9 & $43.7-70.1$ & \\
\hline Low $(1,2$, or 3$)$ & 70.5 & $63.7-77.3$ & 52.9 & $44.9-60.9$ & \\
\hline High (4) & 57.5 & $28.9-86.1$ & 23.0 & $0.0-50.2$ & \\
\hline
\end{tabular}

therapies. More research is needed in this direction to further define the prognostic utility of RhoC.

The clinical significance of elevated RhoC protein in breast cancer is linked to and completely consistent with its biological functions. RhoC is a ras homology gene, with highly conserved motifs and shares a high degree of homology to RhoA, another member of the family [16-18]. Rho proteins in general, and RhoC and RhoA in particular, are involved in cytoskeletal reorganization, specifically in the formation of actin stress fibers and focal adhesion contacts [16-18]. When immortalized human mammary epithelial cells are transfected with RhoC, they undergo a striking change in the cytoplasmic shape and they become motile and invasive [9]. In our laboratory, we discovered the strong link between $\mathrm{RhoC}$ overexpression and inflammatory breast cancer, the most aggressive form of locally advanced breast cancer known [7-9,19]. Thus, it is not surprising that $\mathrm{RhoC}$ overexpression occurs in a small group of biologically aggressive non-IBC tumors with high propensity to recur and metastasize and which respond poorly to doxorubicin-based adjuvant treatment.

Recently, Rho proteins have been implicated in breast tubulogenesis and differentiation, probably through reg- ulation of cell contractility [20]. Our descriptive observations support this notion since RhoC protein levels increased with decreasing differentiation of the invasive carcinomas. For example, well-differentiated invasive carcinomas with prominent tubule formation, monotonous appearing cells, and rare mitoses expressed little or no RhoC protein whereas poorly differentiated carcinomas that grew in disorganized sheets of pleomorphic malignant cells and exhibited a brisk mitotic activity expressed high levels of RhoC protein.

Since our initial reports of $\mathrm{RhoC}$ overexpression in breast cancer our findings have been supported by other investigations. RhoC overexpression has been found in malignancies derived from different cell lineages including non-small cell lung carcinoma, hepatocellular carcinoma, ovarian carcinoma, melanoma, pancreatic carcinoma, and gastric carcinoma [7,10,21-29]. In these malignancies, RhoC has been implicated in neoplastic transformation, progression, invasion, and metastases. Taken together, these data suggest that RhoC may be involved in a global, rather than a tissue type specific mechanism of tumor progression.

Rho proteins are prenylated in order to exert their functions and to localize appropriately to the sub 
Table 7. Univariate analysis of disease free survival

\begin{tabular}{|c|c|c|c|c|c|}
\hline \multirow[t]{2}{*}{ Characteristic } & \multicolumn{2}{|l|}{ 5-year } & \multicolumn{2}{|l|}{ 10-year } & \multirow[t]{2}{*}{ Log-rank $p$-value } \\
\hline & Estimate & $95 \% \mathrm{CI}$ & Estimate & $95 \% \mathrm{CI}$ & \\
\hline Tumor stage & & & & & $<0.0001$ \\
\hline 1 & 96.1 & $90.8-100$ & 90.6 & $81.8-100$ & \\
\hline 2 & 85.7 & $77.0-94.4$ & 67.3 & $54.0-80.5$ & \\
\hline 3 or 4 & 59.4 & $44.3-74.4$ & 48.2 & $31.5-64.9$ & \\
\hline \multicolumn{6}{|l|}{ Tumor size $(\mathrm{cm})$} \\
\hline$\leq 2$ & 90.0 & $83.2-96.7$ & 81.1 & $71.5-90.7$ & 0.0500 \\
\hline$>2$ & 74.3 & $64.3-84.3$ & 66.5 & $55.0-78.1$ & \\
\hline Tumor grade & & & & & 0.0500 \\
\hline $\mathrm{I} / \mathrm{II}$ & 90.6 & $84.7-96.6$ & 77.8 & $68.1-87.5$ & \\
\hline III & 69.3 & $58.3-80.3$ & 59.5 & $47.2-71.9$ & \\
\hline Positive lymph nodes & & & & & $<0.0001$ \\
\hline Zero & 93.5 & $87.9-99.0$ & 86.0 & $77.3-94.7$ & \\
\hline $1-3$ & 82.3 & $70.4-94.3$ & 67.8 & $51.5-84.2$ & \\
\hline $4+$ & 62.0 & $45.4-78.6$ & 46.5 & $26.9-66.1$ & \\
\hline Estrogen receptor & & & & & 0.0041 \\
\hline Positive & 86.6 & $80.1-93.0$ & 74.5 & $65.4-83.7$ & \\
\hline Negative & 64.9 & $52.4-77.3$ & 54.4 & $40.4-68.6$ & \\
\hline Progesterone & & & & & 0.0003 \\
\hline Positive & 92.4 & $86.9-97.9$ & 79.4 & $69.8-89.1$ & \\
\hline Negative & 65.1 & $54.3-75.8$ & 55.2 & $43.1-67.4$ & \\
\hline Lymphovascular invasion & & & & & $<0.0001$ \\
\hline Absent & 87.0 & $80.8-93.3$ & 79.3 & $71.0-87.5$ & \\
\hline Present & 64.4 & $51.8-76.9$ & 47.3 & $32.8-61.8$ & \\
\hline Tamoxifen use & & & & & 0.0121 \\
\hline Yes & 87.8 & $80.7-95.0$ & 80.9 & $71.6-90.2$ & \\
\hline No & 74.9 & $65.8-84.1$ & 60.2 & $48.9-71.6$ & \\
\hline Median RhoC expression & & & & & 0.0736 \\
\hline 1 & 92.1 & $83.1-100$ & 72.7 & $51.4-94.0$ & \\
\hline 2 & 80.2 & $71.4-89.0$ & 72.8 & $62.2-83.4$ & \\
\hline 3 & 78.7 & $68.3-89.1$ & 68.6 & $55.7-81.6$ & \\
\hline Low $(1,2$, or 3$)$ & 81.5 & $75.5-87.4$ & 71.6 & $63.9-79.2$ & \\
\hline High (4) & 64.7 & $36.2-93.2$ & 32.4 & $0.0-67.1$ & \\
\hline
\end{tabular}

(a)

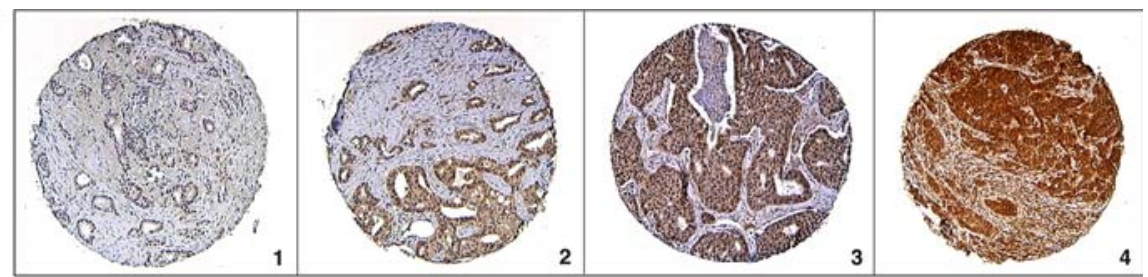

(b) Overall Survival

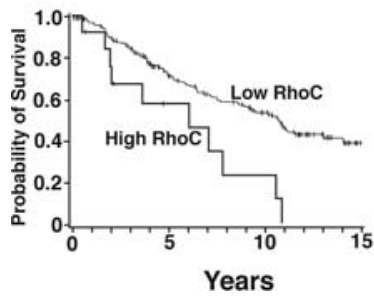

Disease-specific Survival

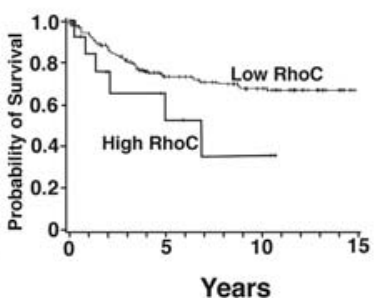

Rho $\mathrm{C}$ in patients treated with chemotherapy

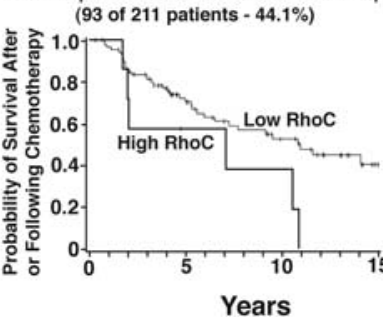

Figure 2. RhoC protein expression is associated with survival in patients with breast cancer. (a) Tissue microarray elements containing representative invasive carcinomas with negative (1), weak (2), moderate (3), and strong (4) RhoC staining intensities. Original magnification 40×. (b) High RhoC expression in invasive carcinomas is associated with worse overall, disease-free, and survival following doxorubicin and cyclophosphamide treatment. 
Table 8. Best multivariate model predicting overall survival

\begin{tabular}{|c|c|c|c|}
\hline Patient/tumor characteristic & HR & $95 \% \mathrm{CI}$ & $p$-Value \\
\hline \multicolumn{4}{|l|}{ Tumor stage } \\
\hline 1 & 1.0 & & \\
\hline 2 & 2.2 & $1.2-4.0$ & 0.0119 \\
\hline 3 or 4 & 5.6 & $2.7-11.5$ & $<0.0001$ \\
\hline \multicolumn{4}{|l|}{ Lymphovascular invasion } \\
\hline Absent & 1.0 & & \\
\hline Present & 1.7 & $0.1-2.7$ & 0.0274 \\
\hline \multicolumn{4}{|l|}{ Progesterone receptor } \\
\hline Positive & 1.0 & & \\
\hline Negative & 1.9 & $1.2-3.1$ & 0.0059 \\
\hline \multicolumn{4}{|l|}{ Median RhoC } \\
\hline Low expression & 1.0 & & \\
\hline High expression & 2.0 & $1.0-4.1$ & 0.0670 \\
\hline \multicolumn{4}{|l|}{ Radiotherapy } \\
\hline No & 1.0 & & \\
\hline Yes & 0.6 & $0.4-1.0$ & 0.0543 \\
\hline \multicolumn{4}{|l|}{ Chemotherapy } \\
\hline No & 1.0 & & \\
\hline Yes & 0.3 & $0.2-0.6$ & 0.0001 \\
\hline \multicolumn{4}{|l|}{ Tamoxifen } \\
\hline No & 1.0 & & \\
\hline Yes & 0.5 & $0.3-0.8$ & 0.0030 \\
\hline
\end{tabular}

Table 9. Best multivariate model predicting overall survival for patients receiving chemotherapy

\begin{tabular}{lccc}
\hline Patient/tumor characteristic & HR & $95 \%$ CI & $p$-value \\
\hline Tumor stage & & & \\
1 & 1.0 & & \\
2 & 1.2 & $0.3-4.3$ & 0.8114 \\
$\quad 3$ or 4 & 4.2 & $1.3-13.9$ & 0.0194 \\
Median RhoC & & & \\
$\quad$ Low expression & 1.0 & & \\
$\quad$ High expression & 3.1 & $1.2-7.7$ & 0.0176 \\
Tamoxifen & & & \\
$\quad$ No & 1.0 & & \\
$\quad$ Yes & 0.4 & $0.2-0.9$ & 0.0374 \\
\hline
\end{tabular}

cytoplasmic membrane space [30-34]. Prenylation can be inhibited by farnesyl transferase inhibitors (FTIs) and FTIs are effective in modulating tumor growth in ras-transformed tumor cells [35-39]. Our group has previously found that FTIs were able to reverse of the RhoC-induced phenotype (even though RhoC is not itself farnesylated), manifested by a significant decrease in anchorage-independent growth, motility, and invasion [39]. Thus, we suggested that FTIs may be useful therapeutic compounds in RhoC overexpressing tumors. Another potentially useful strategy against RhoC phenotypes is represented by the HMGCoA (3-hydroxy-3methylglutaryl-CoA) reductase inhibitors (statins). In particular, atorvastatin has been clearly shown to inhibit RhoC driven phenotypes in melanoma cells [40].
In summary, we discovered that $\mathrm{RhoC}$ expression increases with breast cancer progression and that it is associated with markers of aggressive disease and poor survival. Importantly, we found that $\mathrm{RhoC}$ overexpression is a negative predictor of response to doxorubicin and cyclophosphamide. This work supports that RhoC may have a role in the genesis of a highly aggressive doxorubicin resistant breast cancer phenotype. Our finding that $\mathrm{RhoC}$ overexpression is an infrequent and specific marker of aggressive breast cancer with poor outcome despite treatment may have important clinical implications. Specifically, RhoC detection at the time of primary tumor diagnosis may, in the future, aid clinicians in guiding treatment and paves the way to the development of targeted treatments. While our results are promising, RhoC expression needs to be validated in relationship to outcome in the context of cohorts treated in controlled clinical trials where all patients are treated uniformly. If confirmed, application of RhoC immunohistochemical analysis would be technically straightforward and feasible.

\section{Acknowledgements}

Supported in part by Army grants DAMD17-02-1-0490 (CGK), DAMD17-02-1-491 (CGK), DAMD-17-00-10345 (SDM), NIH grants K08 CA 090876 (CGK), RO1CA10746 (CGK), RO1CA77612 (SDM), 1 P50CADE97258 (SDM), and a grant from the John Suzanne Munn Endowed Research Fund of the University of Michigan Comprehensive Cancer Center (CGK), and NIH grant 5 P30 CA46592 (University of Michigan Cancer Center Support Grant).

\section{References}

1. Jemal A, Murray T, Samuels A, Ghafoor A, Ward E, Thun MJ: Cancer statistics CA Cancer J Clin 53: 5-26, 2003

2. Ellis M, Hayes D, Lippman M: Treatment of metastatic disease. In: Harris J, Lippman ME, Morrow M (eds) Diseases of the Breast. Lippincott-Raven, Philadelpha 2000, pp. 749-798

3. Hayes DF, Isaacs C, Stearns V: Prognostic factors in breast cancer: current and new predictors of metastasis $\mathbf{J}$ Mammary Gland Biol Neoplasia 6: 375-392, 2001

4. Hayes DF, Trock B, Harris AL: Assessing the clinical impact of prognostic factors: when is "statistically significant" clinically useful? Breast Cancer Res Treat 52: 305-319, 1998

5. Clark GM: Prognostic and predictive factors. In: Harris LM. J, Morrow M, Hellman S (eds), Diseases of the Breast. LipponcottRaven Publishers, Philadephia 1996, pp. 461-485

6. Hayes : Do we need prognostic factors in nodal-negative breast cancer? Arbiter Eur J Cancer 36: 302-306, 2000

7. Golen KLvan, Davies S, Wu ZF, Wang Y, Bucana CD, Root H, Chandrasekharappa S, Strawderman M, Ethier SP, Merajver SD: A novel putative low-affinity insulin-like growth factor-binding protein, LIBC (lost in inflammatory breast cancer), and RhoC GTPase correlate with the inflammatory breast cancer phenotype Clin Cancer Res 5: 2511-2519, 1999 
8. Golen KLvan, Wu ZF, Qiao XT, Bao L, Merajver SD: RhoC GTPase overexpression modulates induction of angiogenic factors in breast cells Neoplasia 2: 418-425, 2000

9. Golen KLvan, Wu ZF, Qiao XT, Bao LW, Merajver SD: RhoC GTPase, a novel transforming oncogene for human mammary epithelial cells that partially recapitulates the inflammatory breast cancer phenotype Cancer Res 60: 5832-5838, 2000

10. Kleer CG, Golen KLvan, Zhang Y, Wu ZF, Rubin MA, Merajver $\mathrm{SD}$ : Characterization of RhoC expression in benign and malignant breast disease : a potential new marker for small breast carcinomas with metastatic ability Am J Pathol 160: 579-584, 2002

11. Kleer CG, Cao Q, Varambally S, Shen R, Ota I, Tomlins SA, Ghosh D, Sewalt RG, Otte AP, Hayes DF, Sabel MS, Livant D, Weiss SJ, Rubin MA, Chinnaiyan AM: EZH2 is a marker of aggressive breast cancer and promotes neoplastic transformation of breast epithelial cells Proc Natl Acad Sci USA 100: 11606-11611, 2003

12. Perrone EE, Theoharis C, Mucci NR, Hayasaka S, Taylor JM, Cooney KA, Rubin MA: Tissue microarray assessment of prostate cancer tumor proliferation in African-American and white men J Natl Cancer Inst 92: 937-939, 2000

13. Elston EW, Ellis IO: Method for grading breast cancer $\mathbf{J}$ Clin Pathol 46: 189-190, 1993

14. Manley S, Mucci NR, Marzo AMDe, Rubin MA: Relational database structure to manage high-density tissue microarray data and images for pathology studies focusing on clinical outcome: the prostate specialized program of research excellence model Am J Pathol 159: 837-843, 2001

15. Rhodes DR, Sanda MG, Otte AP, Chinnaiyan AM, Rubin MA Multiplex biomarker approach for determining risk of prostatespecific antigen-defined recurrence of prostate cancer J Natl Cancer Inst 95: 661-668, 2003

16. Nobes CD, Hall A: Rho, rac, and cdc42 GTPases regulate the assembly of multimolecular focal complexes associated with actin stress fibers, lamellipodia, and filopodia Cell 81: 53-62, 1995

17. Hall A, Nobes CD: Rho GT Pases molecular switches that control the organization and dynamics of the actin cytoskeleton Philos Trans R Soc Lond B Biol Sci 355: 965-970, 2000

18. Leung T, Chen XQ, Manser E, Lim L: The p160 RhoA-binding kinase ROK alpha is a member of a kinase family and is involved in the reorganization of the cytoskeleton Mol Cell Biol 16: 53135327, 1996

19. Kleer CG, Zhang Y, Pan Q, Gallagher G, Wu M, Wu ZF, Merajver SD: WISP3 and RhoC guanosine triphosphatase cooperate in the development of inflammatory breast cancer Breast Cancer Res 6: R110-R115, 2004

20. Wozniak MA, Desai R, Solski PA, CJDer, Keely PJ: ROCKgenerated contractility regulates breast epithelial cell differentiation in response to the physical properties of a three-dimensional collagen matrix J Cell Biol 163: 583-595, 2003

21. Suwa H, Ohshio G, Imamura T, Watanabe G, Arii S, Imamura M, Narumiya S, Hiai H, Fukumoto M: Overexpression of the RhoC gene correlates with progression of ductal adenocarcinoma of the pancreas Br J Cancer 77: 147-152, 1998

22. Horiuchi A, Imai $\mathrm{T}$, Wang $\mathrm{C}$, Ohira $\mathrm{S}$, Feng $\mathrm{Y}$, Nikaido $\mathrm{T}$, Konishi I: Up-regulation of small GTPases, RhoA and RhoC, is associated with tumor progression in ovarian carcinoma Lab Invest 83: 861-870, 2003

23. Kamai T, Tsujii T, Arai K, Takagi K, Asami H, Ito Y, Oshima H Significant association of Rho/ROCK pathway with invasion and metastasis of bladder cancer Clin Cancer Res 9: 2632-2641, 2003

24. Kondo T, Sentani K, Oue N, Yoshida K, Nakayama H, Yasui W Expression of RHOC is associated with metastasis of gastric carcinomas Pathobiology 71: 19-25, 2004
25. Shikada Y, Yoshino I, Okamoto T, Fukuyama S, Kameyama T, Maehara $\mathrm{Y}$ : Higher expression of RhoC is related to invasiveness in non-small cell lung carcinoma Clin Cancer Res 9: 5282-5286, 2003

26. Wang W, Yang LY, Yang ZL, Huang GW, Lu WQ: Expression and significance of RhoC gene in hepatocellular carcinoma World J Gastroenterol 9: 1950-1953, 2003

27. Ikoma T, Takahashi T, Nagano S, Li YM, Ohno Y, Ando K, Fujiwara T, Fujiwara H, Kosai K: A definitive role of RhoC in metastasis of orthotopic lung cancer in mice Clin Cancer Res 10: 1192-1200, 2004

28. Clark EA, Golub TR, Lander ES, Hynes RO: Genomic analysis of metastasis reveals an essential role for RhoC Nature 406: 532-535, 2000

29. Carr KM, Bittner M, Trent JM: Gene-expression profiling in human cutaneous melanoma Oncogene 22: 3076-3080, 2003.

30. Seabra MC: Membrane association and targeting of prenylated Ras-like GTPases Cell Signal 10: 167-172, 1998

31. Kirschmeier PT, Whyte D, Wilson O, Bishop WR, Pai JK: In vivo prenylation analysis of Ras and Rho proteins Methods Enzymol 332: 115-127, 2001

32. Adamson P, Marshall CJ, Hall A, Tilbrook PA: Post-translational modifications of p21rho proteins J Biol Chem 267: 20033-20038, 1992

33. Sinensky M: Recent advances in the study of prenylated proteins Biochim Biophys Acta 1484: 93-106, 2000

34. Bishop AL, Hall A: Rho GTPases and their effector proteins Biochem J 348 (Pt2): 241-255 2000

35. Omer CA, Chen Z, Diehl RE, Conner MW, Chen HY, Trumbauer ME, Gopal-Truter S, Seeburger G, Bhimnathwala H, Abrams MT, Davide JP, Ellis MS, Gibbs JB, Greenberg I, Koblan KS, Kral AM, Liu D, Lobell RB, Miller PJ, Mosser SD, O’Neill TJ, Rands E, Schaber MD, Senderak ET, Oliff A, Kohl NE: Mouse mammary tumor virus-Ki-rasB transgenic mice develop mammary carcinomas that can be growth-inhibited by a farnesyl:protein transferase inhibitor Cancer Res 60: 2680-2688, 2000

36. Prendergast GC, Khosravi-Far R, Solski PA, Kurzawa H, Lebowitz PF, CJDer: Critical role of Rho in cell transformation by oncogenic Ras Oncogene 10: 2289-2296, 1995

37. Prendergast GC, Davide JP, deSolms SJ, Giuliani EA, Graham SL, Gibbs JB, Oliff A, Kohl NE: Farnesyltransferase inhibition causes morphological reversion of ras-transformed cells by a complex mechanism that involves regulation of the actin cytoskeleton Mol Cell Biol 14: 4193-4202, 1994

38. Lebowitz PF, Casey PJ, Prendergast GC, Thissen JA: Farnesyltransferase inhibitors alter the prenylation and growth-stimulating function of RhoB J Biol Chem 272: 15591-15594, 1997

39. van Golen KL, Bao L, DiVito MM, Wu Z, Prendergast GC, Merajver SD: Reversion of RhoC GTPase-induced inflammatory breast cancer phenotype by treatment with a farnesyl transferase inhibitor Mol Cancer Ther 1: 575-583, 2002

40. Collisson EA, Kleer C, Wu M, De A, Gambhir SS, Merajver SD, Kolodney MS: Atorvastatin prevents RhoC isoprenylation, invasion, and metastasis in human melanoma cells Mol Cancer Ther 2: 941-948, 2003

Address for offprints and correspondence: C.G. Kleer, 2G332 University Hospital, 1500 E. Medical Center Dr., Ann Arbor, MI 48109-0054; Tel.:+1-734-936-6775; Fax: +1-734-615-3441; E-mail: Kleer@umich. edu 